\title{
Investigation of the hemostatic effects of freeze-dried extracts of selected Kenyan plants
}

\author{
ELIPHAS GITONGA MAKUNYI, FREDERICK BUKACHI", PETER WAWERU \\ School of Medicine, University of Nairobi. Nairobi, Kenya. ^email: fred.bukachi@ghi-net.org; fbukachi@uonbi.ac.ke \\ Manuscript received: 6 August 2019. Revision accepted: 4 February 2019
}

\begin{abstract}
Makunyi EG, Bukachi F, Waweru P. 2019. Investigation of the hemostatic effects of freeze-dried extracts of selected Kenyan plants. Biofarmasi J Nat Prod Biochem 17: 39-46. This study aims to investigate the effect and mechanism of action of freeze-dried extracts of Tridax procumbens, Terminalia brownii, Euphorbia tirucalli, and Asphillia africana on hemostasis. Freeze-dried extract of the selected plants was prepared, and the dose was determined for the study. Twelve male New Zealand white rabbits were randomly allocated to two groups (control and test). Blood was collected under standard procedures. Duke's method was used for the bleeding time, while the capillary method was used for clotting time. ACL Elitepro machine was used to do prothrombin time and activated partial thromboplastin time. Thromboelastography was done for the most potent extracts. Data were analyzed using an independent ttest, and results were presented as mean \pm standard error of means. Differences were considered to be significant if $\mathrm{P}<0.05$. The results showed that the percentage yield of the extract was; Tridax procumbens $(0.8 \%)$, Terminalia brownii $(0.5 \%)$, Euphorbia tirucalli (0.2\%), and Aspillia pluriseta (1.3\%). Bleeding and clotting time: The bleeding time was reduced by freeze-dried leaf extract of Tridax procumbens $(\mathrm{p}=0.0068)$ and freeze-dried bark extract of Terminalia brownii $(\mathrm{p}=0.0068)$. Freeze-dried leaf extract of Asphillia africana increased the bleeding time $(\mathrm{p}=0.01)$. The clotting time was reduced by freeze-dried leaf extract of Tridax procumbens $(\mathrm{p}=0.038)$, the freeze-dried bark extract of Terminalia brownii $(\mathrm{p}=0.043)$, and freeze-dried stem extract of Euphorbia tirucalli $(\mathrm{p}=0.01)$. Prothrombin and activated partial thromboplastin time: The prothrombin time was reduced by freeze-dried leaf extract of Tridax procumbens $(\mathrm{p}=0.004)$, the freeze-dried bark extract of Terminalia brownii $(\mathrm{p}<0.001)$ and Freeze-dried stem extract of Euphorbia tirucalli $(\mathrm{p}=0.001)$. Activated partial thromboplastin time was reduced by freeze-dried leaf extract of Tridax procumbens $(\mathrm{p}<0.001)$, the freeze-dried bark extract of Terminalia brownii $(\mathrm{p}<0.001)$, and by freeze-dried stem extract of Euphorbia tirucalli $(\mathrm{p}<0.001)$. The results for thromboelastography showed that four parameters of thromboelastography were tested. Freeze-dried leaf extract of Tridax procumbens reduced the $r$ time $(p$ $=0.04), \mathrm{k}$ time $(\mathrm{p}=0.04)$ and maximum amplitude $(\mathrm{p}=0.026)$ but increased the alpha angle $(\mathrm{p}=0.01)$. The freeze-dried bark extract of Terminalia brownii did not have statistically significant differences in thromboelastography variables.
\end{abstract}

Keywords: Asphillia africana, Euphorbia tirucalli, freeze-dried extract, hemostatic, Terminalia brownii, Tridax procumbens

\section{INTRODUCTION}

One in seven deaths is associated with traumatic injury, and about a quarter of all trauma admissions present with coagulopathy (Mathew and Richard 2010). It is estimated that more than 1.24 million people die annually due to road traffic accidents globally. In addition, fifty million people suffer injuries from these road traffic accidents (NTSA 2016). In the United States of America, $40 \%$ of trauma fatalities are due to bleeding (Mathew and Richard 2010).

Hemorrhage (bleeding) causes thirty to forty percent of trauma mortality. It accounts for about fifty percent of death in the first 24 hours following the injuries. On admission, $25 \%$ to $35 \%$ of trauma patients present with coagulopathy, which is associated with a sevenfold increase in morbidity and mortality. Coagulopathy is a condition in which the blood's ability to clot is impaired (Brazzel 2013).

According to the World Health Organization (WHO), as many as $80 \%$ of people depend on traditional medicine for their primary health care needs (Essiett and Akpan 2013). Plants are an abundant natural source of potential new medicines. The approach to new drugs through natural products has proved the single most successful strategy for discovering new medicines (Jhample et al., 2009).

The use of herbal preparations for staunching blood flow and reducing the risk of blood disorders is prevalent worldwide (Cordier and Steenkamp 2012). Bleeding in rural setups can be caused by injuries or traditional circumcision. Many plants have been used to prevent bleeding. The plants are either chewed or crushed and then applied to the bleeding sites. Many plants are used, but this study chose the commonly used plants in Eastern Kenya.

The present study investigated the effect and mechanisms of action of Tridax procumbens, Asphillia africana, Euphorbia tirucalli, and Terminalia brownii that have been used traditionally to stop bleeding following cuts and after traditional circumcision by eastern Meru and Embu communities. This study used the leaves of Tridax procumbens and Asphillia africana, the bark of Terminalia brownii, and the stem of Euphorbia tirucalli. The aim of this study is to investigate the effects of freeze-dried extracts of Tridax procumbens, Terminalia brownii, Euphorbia tirucalli, and Asphillia africana on hemostasis. 


\section{MATERIALS AND METHODS}

\section{Extract preparation}

The plants were collected and their identity verified at the University of Nairobi Herbarium, Department of Botany, School of Biological Sciences, and voucher specimens were deposited therein. The plants were airdried, after which they were milled and then macerated with distilled water in a weight volume ratio of 1:4. The resulting suspension was filtered with cotton wool, after which Whatman's filter paper was used. The resulting filtrate was frozen using the Hot Point deep freezer. The frozen filtrate was freeze-dried at the International Centre for Insect Physiology and Ecology (ICIPE). The resulting freeze-dried extract was weighed and then stored in the deep freezer.

\section{Animal preparation and welfare}

Male adult Zealand white rabbits were locally obtained and used for the study. The male rabbits were used because they have almost constant hormonal levels, contrary to females. All the animals weighed $2.0-2.5 \mathrm{~kg}$. They were housed in spacious cages in the animal house, Department of Medical Physiology, University of Nairobi. The room temperature was maintained between $15-25^{\circ} \mathrm{C}$ and relative humidity of $45-65 \%$, a regular 12 hours dark/12hours light cycle. The animals were handled humanely. The selection of rabbits as the experimental animal model ensured adequate blood volume was achieved. Adult male New Zealand white rabbits, $8-12$ weeks old, weighing $2.0-2.5 \mathrm{~kg}$ and healthy, were included, while sick male rabbits were excluded. They were kept under standard laboratory conditions as recommended by The Federation of European Laboratory Animal Science Associations (FELASA) guidelines (Weiss et al. 2010).

\section{Experimental protocol}

Blood was collected using the standard method of bleeding the rabbit from the ear (Duke 1981). For prothrombin time, activated partial thromboplastin time, and thromboelastography, blood was collected in clean citrated bottles and tested within two hours.

The tests were performed using blood from six rabbits for each group (control and test groups). The dose of the freeze-dried extracts was determined using the titration method. The dose of freeze-dried extracts used in most tests was $10 \mathrm{mg} / \mathrm{ml}$. The dosage for the freeze-dried extract of Terminalia brownii for thromboelastography was reduced to $2.5 \mathrm{mg} / \mathrm{ml}$ because doses of $10 \mathrm{mg}, 7.5 \mathrm{mg}$, and $5 \mathrm{mg} / \mathrm{ml}$ were too potent that they only indicated a straight line on thromboelastography. Duke's method of bleeding time was used (Janzarik et al. 1988). The capillary clotting time method was used (Kumar et al., 2013). Prothrombin time and APTT were done at Kenyatta National Hospital Hematology laboratory. The freeze-dried extracts of Tridax procumbens and Terminalia brownii, which were the most potent, were evaluated in the thromboelastography stage.

For thromboelastography, $200 \mu \mathrm{l}$ of sodium citrate was mixed with $1800 \mu \mathrm{l}$ of rabbit's blood. The extract and rabbit blood were mixed at a ratio of 1:4, respectively, after which $360 \mu \mathrm{l}$ of the mixture was loaded into a thromboelastography cup. The ratio is similar to the ratio of the reagents used in thromboelastography. Calcium chloride, $0.2 \mathrm{M}$, was added, and the test was run for one hour.

\section{Data analysis and presentation}

Data were entered into STATA Version 11 and were analyzed using independent t-tests. Results were expressed as means \pm standard error of means (SEM). Differences were considered to be significant if $\mathrm{P}<0.05$.

\section{RESULTS AND DISCUSSION}

\section{Extract yield}

Table 1 shows the percentage yield of the extract, that is, Tridax procumbens leaf $(0.8 \%)$, Terminalia brownii bark (0.5\%), Euphorbia tirucalli stem (0.2\%), and Aspillia africana leaf (1.3\%).

\section{Effect of Tridax procumbens on bleeding time}

Figure 1 shows that the bleeding time is reduced by freeze-dried leaf extract of Tridax procumbens with statistically significant differences in the means (93.6 \pm 7.4 (c) vs. $64.2 \pm 4.5$ ( $\mathrm{t}$ ) seconds, $\mathrm{P}=0.0068, \mathrm{t}=3.39$ ).

\section{Effect of Terminalia brownii on bleeding time}

The freeze-dried bark extract of Terminalia brownii reduced the bleeding time with a statistically significant difference in the means $(100.3 \pm 7$ (c) vs. $82.6 \pm 4.3$ (t) seconds, $\mathrm{p}=0.0068, \mathrm{t}=3.39$ ) (Figure 2).

\section{Effect of Asphillia africana on bleeding time}

Freeze-dried leaf extract of Aspillia africana increased the bleeding time with a statistically significant difference in the means $(107.8 \pm 10.5$ (c) Vs. $152.8 \pm 9.2$ (t) seconds, $\mathrm{t}=3.1 \mathrm{p}=0.01$ ) (Figure 3).

\section{Effect of Tridax procumbens on clotting time}

The result shows that the clotting time is reduced by freeze-dried leaf extract of Tridax procumbens with a statistically significant difference in means $(88.7 \pm 7.8$ (c) vs. $55.7 \pm 26.5$ ( $\mathrm{t}$ ) seconds, $\mathrm{t}=2.45, \mathrm{p}=0.0338$ ) (Figure 4 ).

\section{Effect of Terminalia brownii on clotting time}

Freeze-dried bark extract Terminalia brownii reduced the clotting time with a statistically significant difference in the means $(88.5 \pm 8.7$ (c) vs. $64.2 \pm 9.3$ (t) seconds, $t=1.9$ $\mathrm{p}=0.043$ ) (Figure 5).

Table 1. Extract yield

\begin{tabular}{lccc}
\hline Plant & $\begin{array}{c}\text { Weight of } \\
\text { grounded } \\
\text { product }\end{array}$ & $\begin{array}{c}\text { Weight of } \\
\text { extract } \\
\text { obtained }\end{array}$ & $\begin{array}{c}\text { Percentage } \\
\text { yield }\end{array}$ \\
\hline Tridax procumbens leaves & $500 \mathrm{gm}$ & $4 \mathrm{gm}$ & 0.8 \\
Terminalia brownii bark & $2 \mathrm{~kg}$ & $10 \mathrm{gm}$ & 0.5 \\
Euphorbia tirucalli stem & $1 \mathrm{~kg}$ & $2 \mathrm{gm}$ & 0.2 \\
Asphillia Africana leaves & $300 \mathrm{gm}$ & $4 \mathrm{gm}$ & 1.3 \\
\hline
\end{tabular}


Effect of Euphorbia tirucalli on clotting time

Freeze-dried stem extract of Euphorbia tirucalli reduced the clotting time with a statistically significant difference in means $(88.5 \pm 8.7$ (c) vs. $57 \pm 9.7$ (t) seconds, $\mathrm{t}=2.4 \mathrm{p}=0.01$ ) (Figure 6).

\section{Effect of Tridax procumbens on prothrombintime}

The results show that the prothrombin time is reduced by freeze-dried leaf extract of Tridax procumbens with a statistically significant difference in the means $(9.4 \pm 0.17$ (c) vs. 5.3 \pm 0.17 (t) seconds, $\mathrm{t}=5.12, \mathrm{p}=0.004$ ) (Figure 7).

\section{Effect of Terminalia brownii on prothrombin time}

The freeze-dried bark extract of Terminalia brownii reduced the prothrombin time with a statistically significant difference in the means $(9.4 \pm 0.78$ (c) vs. $3.8 \pm 0.38$ (t) seconds, $\mathrm{t}=6.4, \mathrm{p}<0.001$ ) (Figure 8).

\section{Effect of Euphorbia tirucalli on prothrombin time}

Freeze-dried stem extract of Euphorbia tirucalli reduced the prothrombin time with a statistically significant difference in the means $(5.8 \pm 0.17$ (c) vs. $9.4 \pm 0.78$ (t) seconds, $\mathrm{t}=4.6, \mathrm{p}=0.001$ ) (Figure 9).

\section{Effect of Tridax procumbens on Activated partial thromboplastin time}

The result showed that the APTT was reduced by freeze-dried leaf extract of Tridax procumbens with a statistically significant difference in the means $(25.8 \pm 1.3$ (c) vs. 8.3 $\pm 1.6(\mathrm{t})$ seconds, $\mathrm{t}=8.53, \mathrm{p}<0.001$ ) (Figure 10).

\section{Effect of Terminalia brownii on activated partial thromboplastintime}

The freeze-dried bark extract of Terminalia brownii reduced the APTT with a statistically significant difference in the means of the treatment group $(22.14 \pm 0.84$ (c) vs. $4.2+0.48$ (t) seconds, $\mathrm{t}=18, \mathrm{p}<0.001)$ (Figure 11).

\section{Effect of Euphorbia tirucalli Activated partial thromboplastintime}

Freeze-dried stem extract of Euphorbia tirucalli decreased the APTT with a statistically significant difference in means $(22.1 \pm 0.84(\mathrm{c})$ vs. $5.7 \pm 0.31(\mathrm{t}), \mathrm{t}=18$, $\mathrm{p}<0.001$ ) (Figure 12).

\section{Effect of Tridax procumbens on $r$-time}

The results indicate that freeze-dried leaf extract of Tridax procumbens decreased the time with a statistically significant difference in the means $(6.2 \pm 1.6$ (c) vs. $2.7 \pm 0.49(\mathrm{t})$ minutes, $\mathrm{t}=2.08, \mathrm{p}=0.04$ ) (Figure 13).

\section{Effect of Terminalia brownii on r-time}

The freeze-dried bark extract of Terminalia brownii did not elicit a statistically significant difference in the means of $r$ time $(4.9 \pm 1.6$ (c) vs. $5.3 \pm 0.9$ (t) minutes, $t=0.17$ $\mathrm{p}=0.86)$ (Figure 14).

\section{Effect of Tridax procumbens on k-time}

The results indicate freeze-dried leaf extract of Tridax procumbens decreases the $\mathrm{k}$ time with a statistically significant difference in the means $(3.7 \pm 1.1$ (c) vs. $1.4 \pm 0.18(\mathrm{t})$ minutes, $\mathrm{p}=0.04 \mathrm{t}=2.03$ ) (Figure 15).

\section{Effect of Terminalia brownii on $k$-time}

The freeze-dried bark extract of Terminalia brownii did not elicit a statistically significant difference in the means of $\mathrm{k}$ time $(1.3 \pm 0.26$ (c) vs. $2.2 \pm 0.6$ (t) minutes, $\mathrm{t}=1.47$, $\mathrm{p}=0.21)$ (Figure 16).

\section{Effect of Tridax procumbens on the alpha angle}

The results indicate freeze-dried leaf extract of Tridax procumbens increases the alpha angle with a statistically significant difference in the means $(43.3 \pm 6.9$ (c) vs. 69.9 $\pm 2.51(\mathrm{t})$ degrees, $\mathrm{t}=3.65, \mathrm{p}=0.01)$ (Figure 17).

\section{Effect of Terminalia brownii on the alpha angle}

The freeze-dried bark extract of Terminalia brownii did not elicit a statistically significant difference in the means of alpha angle $(69.1 \pm 3.4$ (c) vs. $51.3 \pm 10.8(\mathrm{t})$ degrees, $\mathrm{t}=1.6$ $\mathrm{p}=0.08)$ (Figure 18).

\section{Effect of Tridax procumbens on the maximum amplitude}

The results indicated freeze-dried leaf extract of Tridax procumbens increased the maximum amplitude with a statistically significant difference in the means $(62.4 \pm 5.6$ (c) vs. $34.8 \pm 7.6$ (t) mm, t=3.65, p=0.026) (Figure 19).

\section{Effect of Terminalia brownii on the maximumamplitude}

The freeze-dried bark extract of Terminalia brownii did not elicit a statistically significant difference in the means of maximum amplitude $(61.5 \pm 2.8$ (c) vs. $46.9 \pm 9.7$ (t) $\mathrm{mm}$, $\mathrm{t}=1.44, \mathrm{p}=0.19$ ) (Figure 20).

\section{Discussion}

Coagulation requires complex interactions of cellular and molecular components that mainly involve platelets, plasma, and red blood cells (Hoffman and Monroe 2007). Initially, clotting involved intrinsic and extrinsic pathways with a common pathway at the end. Still, lately, it has been noted to be due to a balance between pro-coagulants and anti-coagulants (Hoffman and Monroe 2007). It involves the interaction of coagulation factors and platelets. Coagulation status can be measured using laboratory tests. The hemostatic effects of four Kenyan plant extracts (Tridax procumbens, Terminalia brownii, Euphorbobia tirucalli, and Asphillia africana) were elucidated using five laboratory tests; bleeding time, clotting time, prothrombin time, activated partial thromboplastin time (APTT) and thromboelastography. Bleeding time assesses the capillary integrity and platelet function. Clotting time measures the time taken to generate thrombin. Prothrombin time mainly measures the effect on the extrinsic pathway and is more sensitive to factor VII. Activated partial thromboplastin time evaluates the effect of the intrinsic pathway factors. 


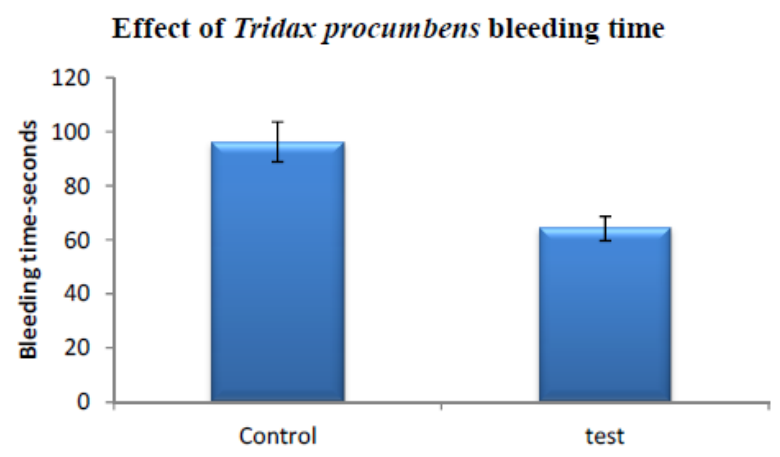

Figure 1. Effect of Tridax procumbens on bleeding time

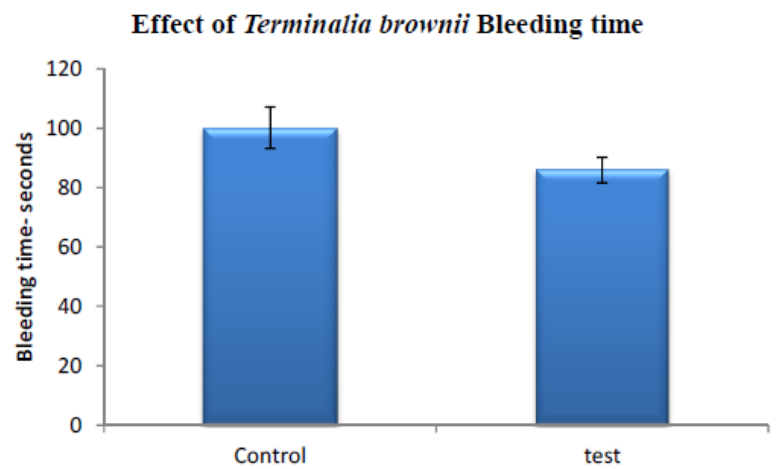

Figure 2. Effect of Terminalia brownii on bleeding time

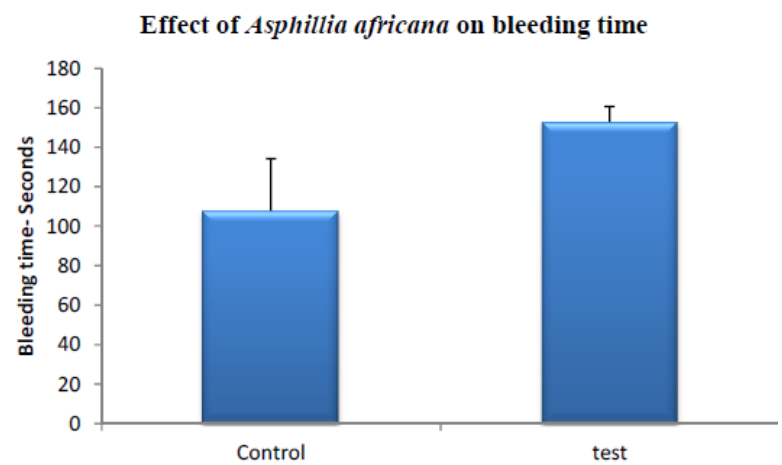

Figure 3. Effect of Asphillia africana on bleeding time

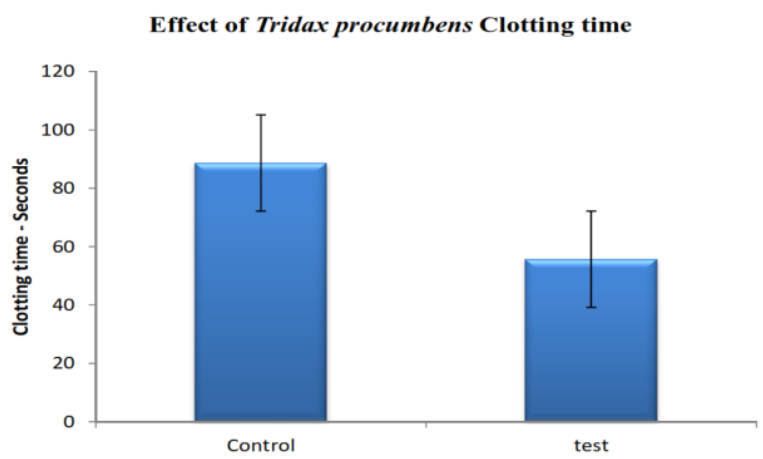

Figure 4. Effect of Tridax procumbens on clotting time
Effect of Terminalia Brownii Clotting time

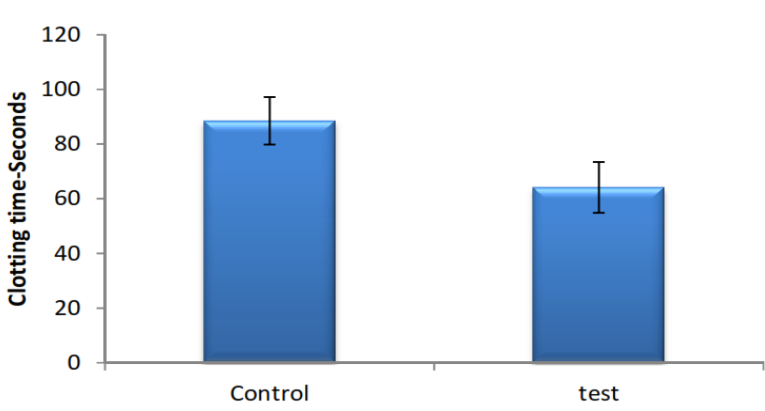

Figure 5. Effect of Terminalia brownii on clotting time

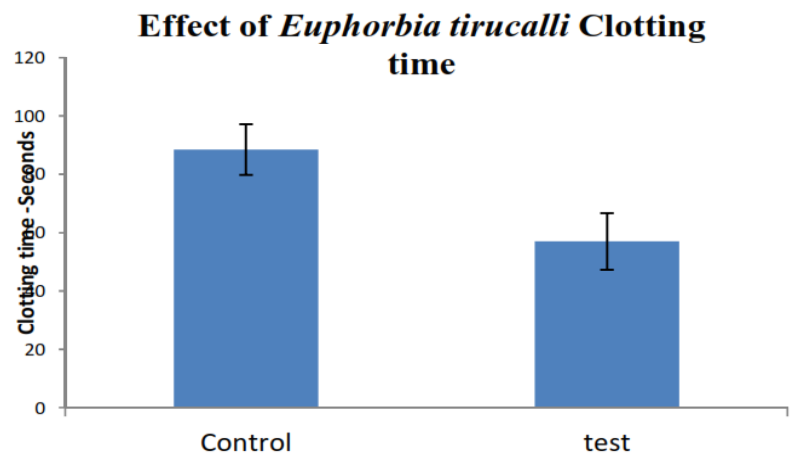

Figure 6. Effect of Euphorbia tirucalli on clotting time

Effect of Tridax procumbens Prothrombin time

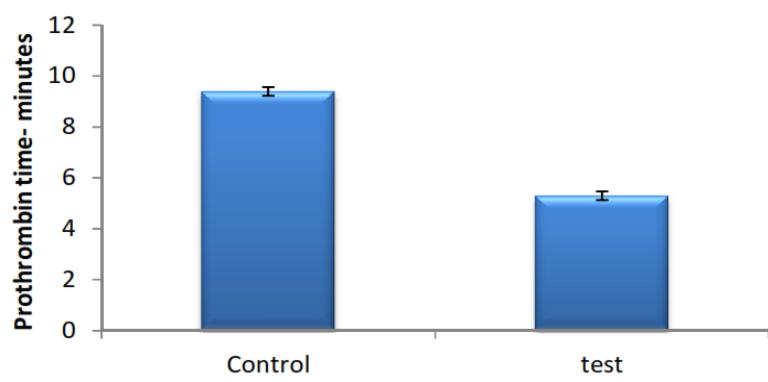

Figure 7. Effect of Tridax procumbens on prothrombin time

Effect of Terminalia brownii prothrombin time

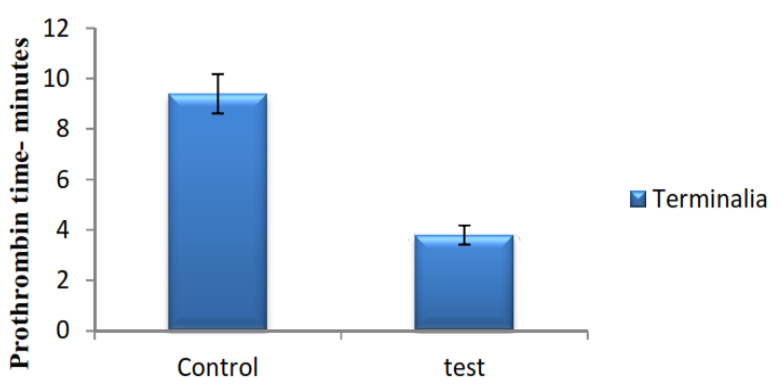

Figure 8. Effect of Terminalia brownii on prothrombin time 


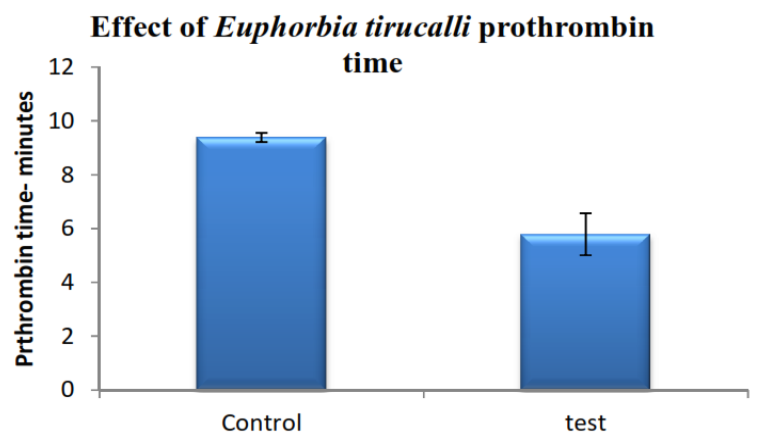

Figure 9. Effect of Euphorbia tirucalli on prothrombin time

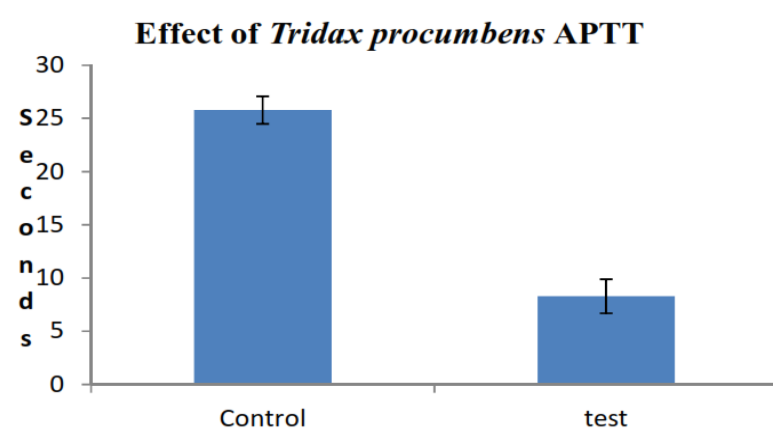

Figure 10. Effect of Tridax procumbens on Activated Partial Thromboplastin Time

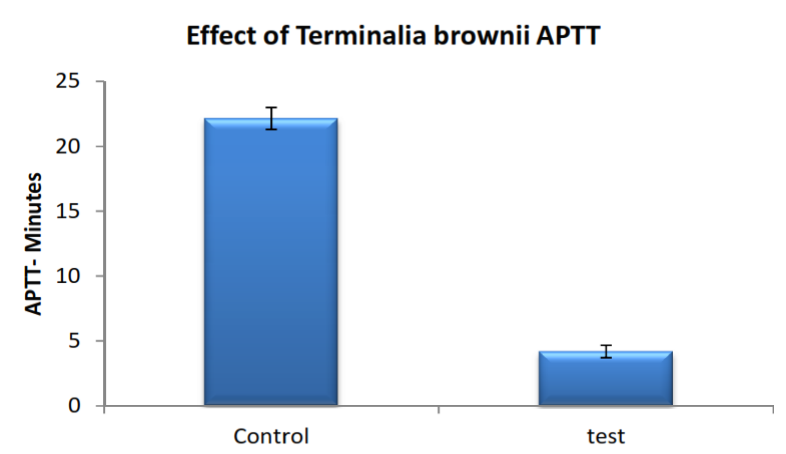

Figure 11. Effect of Terminalia brownii on Activated Partial Thromboplastin Time

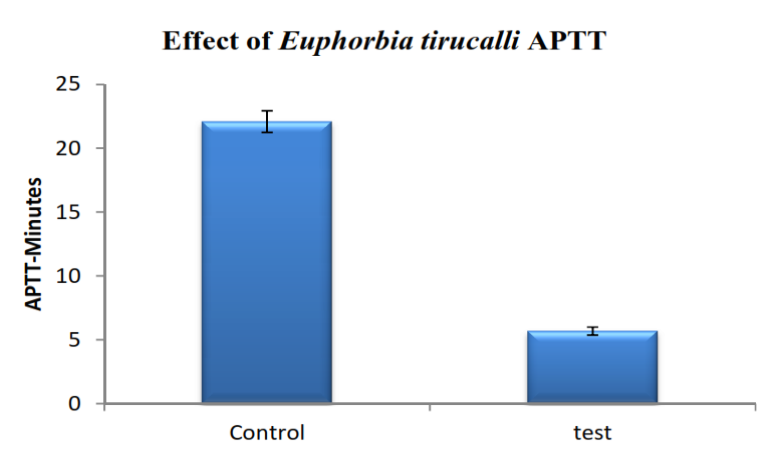

Figure 12. Effect of Euphorbia tirucalli Activated Partial Thromboplastin Time

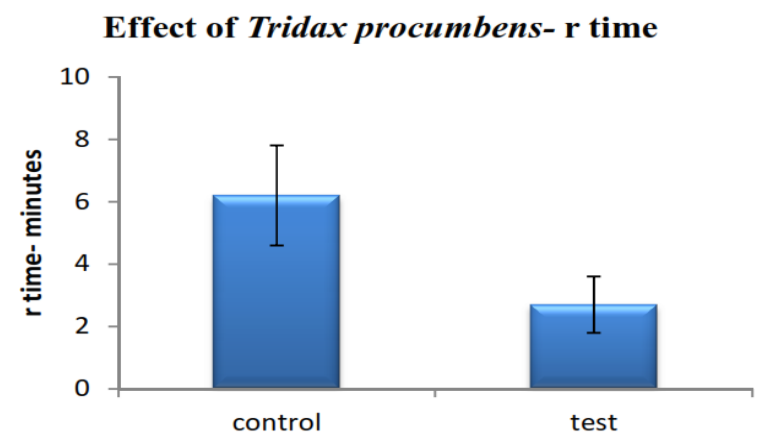

Figure 13. Effect of Tridax procumbens on r- time

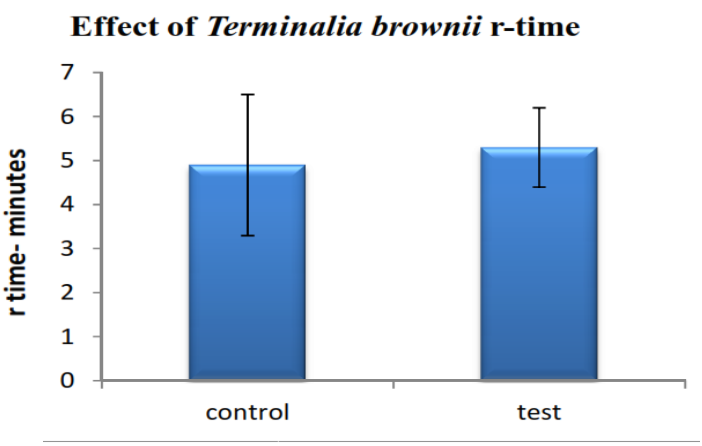

Figure 14. Effect of Terminalia brownii on r-time

Effect of Tridax procumbens $k$ time

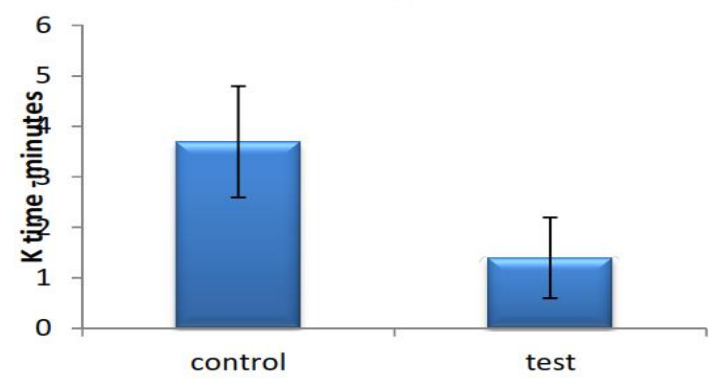

Figure 15. Effect of Tridax procumbens on K- time

Effect of Terminalia brownii k time

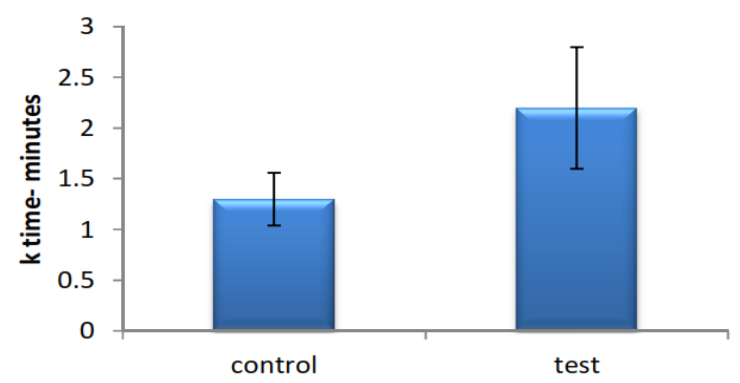

Figure 16. Effect of Terminalia brownii on k time 


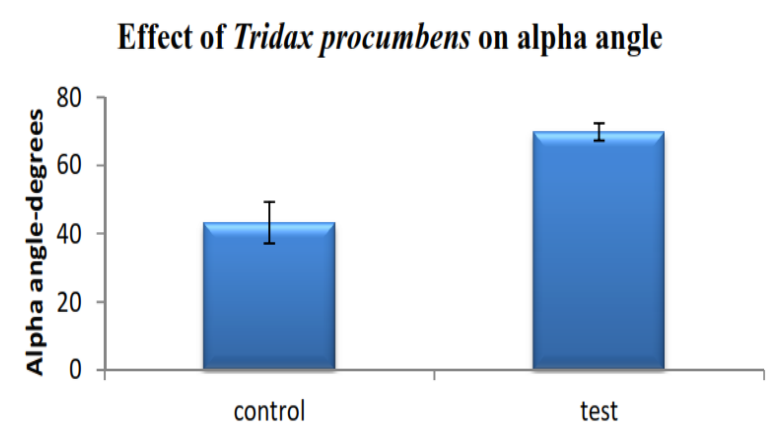

Figure 17. Effect of Tridax procumbens on the alpha angle

Effect of Terminalia Brownii alpha angle

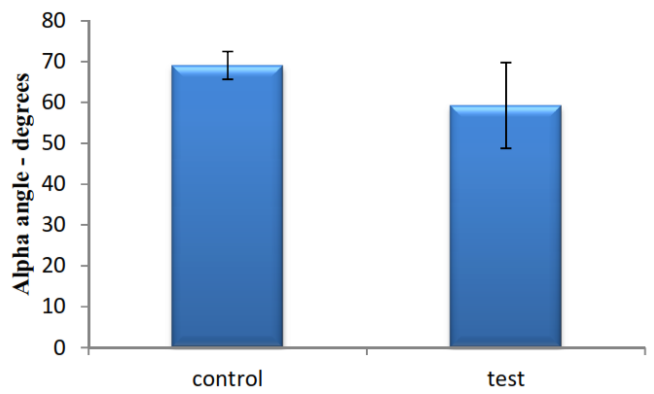

Figure 18. Effect of Terminalia brownii on the alpha angle

\section{Effect of Tridax procumbens maximum amplitude}

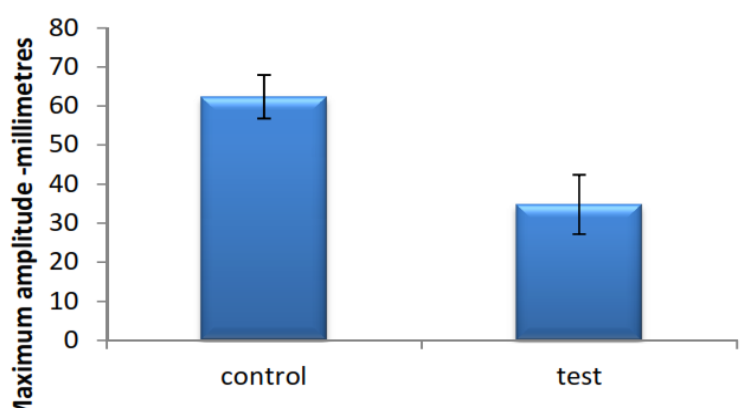

Figure 19. Effect of Tridax procumbens on the maximum amplitude

\section{Effect of Terminalia brownii maximum amplitude}

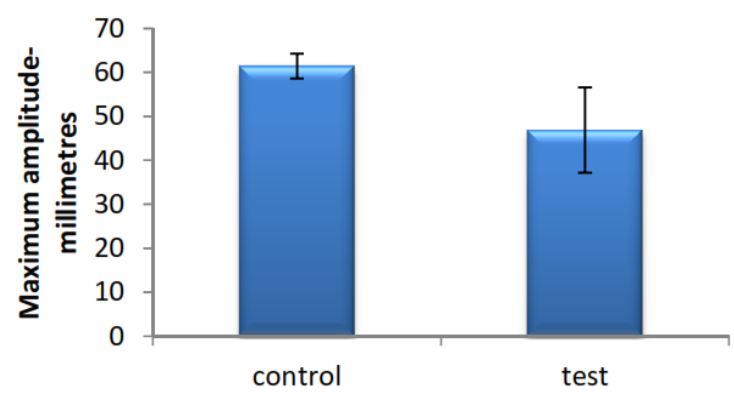

Figure 20. Effect of Terminalia brownii on the maximum amplitude
The freeze-dried leaf extract of Tridax procumbens significantly reduced the bleeding time (Fig.1). Ikese et al. (2015) confirm these findings, who found that a freezedried extract of Tridax procumbens significantly decreased bleeding time. The results are also similar to the ethanolic extracts of the same plant shown to reduce the bleeding time (Manjusha et al. 2014), which reflects platelet function (Kumar et al. 2013). This plant has potential activation effects on the platelets.

The freeze-dried bark extract of Terminalia brownii reduced the bleeding time (Figure 2). These are new findings on this plant that have previously not been reported. Bleeding time indicates the platelet function (Kumar et al. 2013), and therefore, this plant may have activation effects on the platelets.

The freeze-dried leaf extract of Asphillia africana increased the bleeding time (Figure 3). These findings were unexpected because other studies demonstrated that it reduces bleeding time. These findings are contrary to Okoli et al. (2007), which showed that methanol and hexane of Asphillia africana extract reduced bleeding time. Bleeding time indicates the platelet function (Kumar et al. 2013), and therefore, this plant may have an inhibitory effect on platelet function.

The freeze-dried leaf extract of Tridax procumbens significantly reduced the clotting time (Figure 4). This confirms the results of a similar study in which an aqueous extract reduced the clotting time (Ikese et al., 2015). The results are also identical to pet ether extract of the same plant, which significantly reduced the clotting time (Manjusha et al. 2014). The results are similar to those of Kale et al. (2008), which showed that ethanolic leaf extracts reduced the clotting time. Jhample et al. (2015) also demonstrated that the plant extract reduced the clotting time. Clotting time reflects the time to generate clotting factors, specifically thrombin, to form a clot (Hoffman and Monroe 2007). Therefore, this plant may have activation affect clotting factors that lead to thrombin formation.

The freeze-dried bark extract of Terminalia brownii reduced the clotting time (Figure 5). These are new findings on this plant that have previously not been reported. Clotting time reflects the time taken to generate clotting factors, specifically thrombin, to form a clot (Hoffman and Monroe 2007). Therefore, this plant could have activation effects on clotting factors that lead to thrombin formation.

The freeze-dried stem extract of Euphorbobia tirucalli reduced the clotting time (Figure 6). These are new findings on this plant that have previously not been reported. Clotting time reflects the time taken to generate clotting factors, specifically thrombin, to form a clot (Hoffman and Monroe 2007). Therefore, this plant may have some activation effects on clotting factors leading to thrombin formation.

The freeze-dried leaf extract of Tridax procumbens reduced the prothrombin time (Figure 7). These are new findings that have previously not been reported. Prothrombin time evaluates the extrinsic pathway (Hoffman and Monroe 2007), and therefore, this plant 
extract may have some activation effects on the external pathway coagulation factor.

The freeze-dried bark extract of Terminalia brownii reduced the prothrombin time (Figure 8). These are new findings on this plant that have previously not been reported. Prothrombin time evaluates the extrinsic pathway (Hoffman and Monroe 2007), and therefore, this plant extract may have activation effects on the extrinsic pathway coagulation factor. The freeze-dried stem extract of Euphorbobia tirucalli significantly reduced the prothrombin time (Figure 9). These are new findings on this plant. Prothrombin time evaluates the extrinsic pathway (Hoffman and Monroe 2007), and therefore, this plant extract may have activation effects on the extrinsic pathway coagulation factor.

The freeze-dried leaf extract of Tridax procumbens reduced the activated partial thromboplastin time (Figure 10). These are new findings that have previously not been reported. Activated partial thromboplastin time evaluates the intrinsic pathway (Hoffman and Monroe 2007), and therefore, this plant extract has an activation effect on intrinsic pathway factors.

The freeze-dried bark extract of Terminalia brownii reduced the activated partial thromboplastin time (Figure 11). These are new findings on this plant that have previously not been reported. Activated partial thromboplastin time evaluates the intrinsic pathway (Hoffman and Monroe 2007), and therefore, this plant extract has an activation effect on intrinsic pathway factors.

The freeze-dried stem extract of Euphorbobia tirucalli reduced the activated partial thromboplastin time (Figure 12). These are new findings on this plant that have previously not been reported. Activated partial thromboplastin evaluates the intrinsic pathway (Hoffman and Monroe 2007), and therefore, this plant extract has an activation effect on intrinsic pathway factors.

Freeze-dried extracts of Terminalia brownii and Tridax procumbens were noted to be most potent among the group and were used during thromboelastography (Figure 12-20). Thromboelastography generated four variables; r, k times, alpha angle, and maximum amplitude. The $r$ time evaluated the time of initiation of a clot of $2 \mathrm{~mm}$ amplitude. At 'initiation,' the Tissue Factor binds to circulating FVIIa and acts with FV to generate FIXa and FXa. The k- time evaluated the time taken for clot amplitude of $2 \mathrm{~mm}$ to reach $20 \mathrm{~mm}$. This involves the interaction of clotting factors and platelets. During the 'amplification' of a clot, thrombin triggers reactions on the surface of activated platelets, where more FVIIa is produced. Thrombin activates co-factors FV and FVIII. The alpha angle measured the speed of clot strengthening. This mainly involves the interaction of fibrin and platelets. The maximum amplitude measures the ultimate clot strength. This includes mostly platelet function. In the hypercoagulable state, the $\mathrm{r}$ and $\mathrm{k}$ times decrease, and the maximum amplitude increase during the alpha angle.

The freeze-dried leaf extract of Tridax procumbens significantly reduced the r-time, k-time, and maximum clot amplitude but increased the $\alpha$ angle. These are novel findings that have previously not been reported. Thus, the plant extract acts on the clotting factors mainly in the extrinsic pathway and does not have much effect on the platelets. Factor VII is the main factor in the initiation of clot formation in the extrinsic pathway (Hoffman and Monroe 2007).

Freeze-dried bark extract at a dose of $2.5 \mathrm{mg} / \mathrm{ml}$ of Terminalia brownii increased the r-time, k-time, and maximum amplitude. Still, it decreased the alpha angle, though none of the changes were statistically significant. Doses of $10 \mathrm{mg} / \mathrm{ml}, 7.5 \mathrm{mg} / \mathrm{ml}$, and $5 \mathrm{mg} / \mathrm{mg}$ caused rapid coagulation that indicated a straight line on thromboelastography. The lower dose produced opposite results may be due to the disproportional interaction of the extract molecules and the coagulation factors. This is the first time this study has been done on this plant. The limitation of the study was that the platelet aggregation test that would have indicated the effect of Tridax procumbens on coagulation was not possible because of time and logistical considerations.

In conclusion, freeze-dried leaf extracts of Tridax procumbens and freeze-dried bark extract of Terminalia brownii have some activation effect on the platelets. They have a stimulatory effect on the capillary muscles. Freezedried extract of Asphillia africana has an anti-coagulant impact contrary to traditional perceptions of it being procoagulant. Freeze-dried leaf extract of Tridax procumbens, freeze-dried stem extract of Euphorbia tirucalli, and freeze-dried bark extract of Terminalia brownii have some activation effects on both extrinsic and intrinsic coagulation pathways. Freeze-dried leaf extract of Tridax procumbens has more effect on factor VII, which is involved in the initiation of clot formation. Tridax procumbens, Terminalia brownii, and Euphorbia tirucalli are potential plants for developing drugs that can be used to reduce bleeding. The present research recommends further studies on Tridax procumbens to assess the active molecule in coagulation, which can further be evaluated for drug development. A platelet aggregation test for the freezedried extracts should also be carried out to verify the low platelet effect seen in thromboelastography.

\section{REFERENCES}

Brazzel C. 2013. Thromboelastography-guided transfusion Therapy in the trauma patient. AANA J 81 (2):127-132

Cordier W, Steenkamp V. 2012. Herbal remedies affecting coagulation: A review. Pharmaceut Biol 50 (4): 443-452. DOI: 10.3109/13880209.2011.611145.

Duke JA. 1981. The gene revolution. Paper 1. In: Office of Technology Assessment, Background papers for innovative biological technologies for lesser developed countries. USGPO, Washington.

Essiett U, Akpan EM. 2013. Proximate composition and phytochemical constituents of Aspilia africana (Pers) CD Adams and Tithonia diversifolia (Hemsl) A. Gray stems (Asteraceae). Bull Environ Pharmacol Life Sci 2 (4): 33-37.

Hoffman M, Monroe D. 2007. Coagulation 2006: A modern view of hemostasis. Hematol/Oncol Clin North Am 21 (1): 1-11. DOI: 10.1016/j.hoc.2006.11.004

Ikese Z, Kukwa1 D, Adogal S, Lenka J. 2015. Effect of aqueous leaf extract of Tridax procumbens on blood coagulation. Intl J Pharm Sci Res 6 (8): 3391-3395.

Janzarik H, Remy S, Morell S, Pabst W. 1986. Haemostasis time, a modified bleeding time test and its comparison with the duke and 
IVY/template bleeding times. Blut 52 (6): 345-356. DOI: 10.1007/BF00320781.

Jhample SB, Gajdhane SB, Kasabe PJ, Bhagwat PK, Dandge PB. 2015. Phytochemical screening and in vitro antimicrobial activity of Tridax procumbens L. Res J Life Sci Bioinform Pharm Chem Sci 1 (1): 42 51.

Kale MA, Shahi SR, Somani VG, Shamkuwar PB, Dhake AS. 2008. Hemostatic activity of the leaves of Tridax procumbens Linn. Intl J Green Pharm 2 (1). DOI: 10.4103/0973-8258.39167.

Kumar S, George J, Mukkadan J. 2013. Bleeding time and clotting time in healthy male and female college students of Karukutty Village, Kerala. Health Prospect 12 (1). DOI: 10.3126/hprospect.v12i1.8720

Manjusha B, Ujjwala K, Harish L, Apurva M, Rita D, Yashavant D. 2014 Effect of various extracts of leaves of Tridax procumbens on human blood clotting time: A comparative in vitro study. J Nat Prod Plant Resour 4: 9-14.

Mathew R, Richard P. 2010. Management induced coagulopathy: trends and practices. AANA J 78 (1): 35-40.

NTSA (National Transport Safety Authority). 2016. Status report. Government of Kenya, Nairobi.

Okoli C, Akah P, Nwafor S, Anisiobi A, Ibegbunam I, Erojikwe O. 2007. Anti-inflammatory activity of hexane leaf extract of Aspilia africana CD Adams. J Ethnopharmacol 109: 219-225. DOI: 10.1016/j.jep.2006.07.037

Weiss J, Bukelskiene V, Chambrier P, Ferrari M, Meulen M, Moreno M, Sigg H, Yates N. 2010. FELASA recommendations for the education and training of laboratory animal technicians: category A. Lab Anim 44: 163-169. DOI: 10.1258/la.2010.010004. 